\title{
Reading fluency performance of elementary-school fifth-grade students
}

\author{
Cláudia da Silva ${ }^{1}$ \\ https://orcid.org/0000-0003-3091-8448
}

Beatriz Vieira da Fonseca ${ }^{2}$

https://orcid.org/0000-0001-6679-7380

Universidade Federal Fluminense - UFF, Departamento de Formação Específica em Fonoaudiologia, Nova Friburgo, Rio de Janeiro, Brasil.

2 Universidade Federal Fluminense - UFF, Curso de Graduação em Fonoaudiologia Nova Friburgo, Rio de Janeiro, Brasil.

This study was carried out at the Health Institute of Nova Friburgo by the Department of Speech-Language-Hearing Specific Training - FEF of the Universidade Federal Fluminense - UFF, Nova Friburgo, Rio de Janeiro, Brazil.

Conflict of interests: Nonexistent

\section{(c) (i)}

Received on: October 8, 2021 Accepted on: November 15, 2021

Corresponding address: Cláudia da Silva

Avenida Alberto Braune, 160, apto. 409 CEP: 28613-000 - Nova Friburgo,

Rio de Janeiro, Brazil

E-mail: claudiasilvafono@yahoo.com.br

\section{ABSTRACT}

Purpose: to characterize and compare the reading fluency performance of public- and private-school fifth-grade students.

Methods: a total of 44 elementary-school fifth-grade students of both sexes, aged 10 to 11 years, participated in the study and were divided into Group I (Gl, with 25 public-school students) and Group II (GIl, with 19 private school students). They were submitted to the Assessment of Reading Fluency Performance (ADFLU). The performance analysis was based on the number of correct words per minute, incorrect words per minute, total reading time, and reading speed. The data analysis was made with statistical tests, with significance set at $p$-value $\leq 0.05$, for the inter- and intragroup comparisons.

Results: in the analysis per group, there was a significant difference in the total reading time between the texts in $\mathrm{Gl}$, and in the reading speed between the texts, in Gll. In the comparison between the groups, all variables had a significant difference, with a better performance in Gll.

Conclusion: the reading fluency performance of public- and private-school fifth-graders was characterized. The performance of the private-school students was superior to that of the public-school students.

Keywords: Learning; Reading; Learning Disabilities; Education 


\section{INTRODUCTION}

Learning to read is a complex task which involves neurobiological processes and cognitive skills, which develop and broaden throughout life with formal and guided teaching. Reading is directly related to the access to information (letter/sound) via working memory (to decode signs) and long-term memory (to make inferences that aid text comprehension) $)^{1,2}$.

The process of learning to read, from decoding to apprehending the meaning, requires the development of metalinguistic skills. These can be classified into subgroups, namely: phonological awareness (to perceive the phoneme), morphological awareness (to form words), syntactic awareness (to form sentences with the proper agreement, subordination, and order), pragmatic awareness (associated with the context in which the information is employed), and metatextual awareness (referring to the ability to reflect on the properties that form the text) ${ }^{3-5}$.

Hence, reading begins with the storage, recognition, and recovery of letters to form words. Following this process, the words must be understood in simple or complex sentences until they can be presented in small texts, with a meaning. Adding contents to what a person has already learned implies associating information previously acquired with information extracted from the text they have read. They also need to interpret and make inferences, which is a unique and personal process, consolidated with information external to the person $^{6,7}$.

Many theories have been proposed for learning to read Brazilian Portuguese. One of them is the dual-route model, which has been largely studied and is one of the most accepted in the literature. This model consists of approaching two routes - the phonological and the lexical routes - which play a role in the decoding process. The phonological route is responsible for decoding signs, via grapheme-phoneme conversion, used when one is learning to read and write and when infrequent and irregular words need to be decoded ${ }^{1,8}$.

The lexical route, in its turn, is accessed through visual information of words stored in the lexical memory, in which the meaning is obtained via the semantic system - i.e., through the access to information present in the person's lexicon, enabling the immediate identification of the word belonging to the reader's lexicon. Hence, the two routes are complementary to the decoding process and equally important for the reader to be fluent, as proficient readers normally use both routes in decoding ${ }^{9,10}$.
The grapheme-phoneme decoding process is based on previous learning, which over time becomes automatic, characterizing reading fluency. This, in turn, depends on three main factors: accurate decoding, speed, and prosody. Accurate word decoding is the precise grapheme-phoneme conversion, while speed is related to the automatic processing - as reading must be adequate and rhythmic according to the punctuations in the text. Prosody encompasses the pauses and intonations in reading, which may even interfere with the interpretation of the text. Therefore, for reading to be fluent, it must be easy and smooth to the reader ${ }^{11}$.

Hence, based on decoding and inferencing, the skillful reader can obtain an overall comprehension of what they have read. However, it requires the comprehension of words, which are connected in sequence to provide text comprehension. This can be segmented into text macro- and microstructure ${ }^{12,13}$.

In short, the text macrostructure is the global content present in the text - i.e., the coherence, topic, and main ideas in the text. The text microstructure, on the other hand, encompasses the details in the text - the words chosen, their use frequency, and the grammatical resources. Hence, it brings more specific information regarding the main theme. Both are better interpreted with competent text reading, which makes fluent reading essential to improve more general and specific text comprehension ${ }^{14}$.

Recent research ${ }^{5,10,11}$ points out a relationship between reading fluency and comprehension. When children acquire reading automaticity, they use only the working and long-term memory to understand what they are reading. Thus, the reader no longer needs to make a great cognitive effort when decoding orthographic signs - i.e., they turn their attention and concentration mechanisms to text comprehension ${ }^{15-17}$.

According to the Organization for Economic Cooperation and Development (OECD, 2019) ${ }^{18}$, the reading performance of Brazilian students in the Program for International Student Assessment (PISA) is below the expected, with a score of 413 points in 2018, inferior to the standard average of 487 points.

Therefore, fluent reading is extremely important to fifth-grade students because it is their last year in elementary school. It must be approached as a preparation for middle school, which will introduce them to new academic content requiring greater involvement between fluent reading and comprehension. Also, the cognitive demands are greater, as they are required to learn more content with less time to do the tasks. 
Hence, students who finish fifth grade with adequate reading fluency performance are more likely to acquire and develop the skills related to learning it, as well as the comprehension and interpretation of what they read in the textbooks $2,12,17,19,20$.

Reading fluency is expected to evolve as the person advances to the subsequent grades in school, increasing the number of correct words per minute (CWPM), as the reader becomes proficient in this skill5. Thus, the survey of parameters related to the number of correct words produced by readers in the learning process helps identify which students need intervention and which ones are acquiring the reading processes as expected.

To this end, assessment parameters related to the CWPM, the number of incorrect words per minute (IWPM), total reading time (TRT), and reading speed (RS) need to be established, addressing the main grades in elementary school in Brazil, in the different teaching methods. Based on this assumption, there is an effort to identify reading fluency parameters for fifthgraders of both the public and private school systems, approaching two schools in the state of Rio de Janeiro. While it aims to identify values to help guide reading fluency in fifth graders, no procedures or specific reading assessments address this specific grade which would help identify both reading and reading fluency deficits before they get to middle school.

Thus, this study aimed at characterizing and comparing the reading fluency performance of fifthgrade students attending public and private elementary schools.

\section{METHODS}

This is a quantitative, observational, cross-sectional study. The project was approved by the Research Ethics Committee of the Universidade Federal Fluminense - UFF, Brazil, under number 2.956.909. The participating institution signed a form authorizing the research, and informed consent and assent forms were handed to and signed by the parents/guardians of the research participants, as stipulated by the resolution of the National Health Council - CNS 466/2012.

The research was carried out with elementary-school fifth graders of both sexes, aged 10 to 11 years, to survey their reading fluency performance. The students were distributed into two groups, namely: Group I (GI), with 25 public-school fifth graders, and Group II (GII), with 19 private-school fifth graders.
The students were selected based on preestablished inclusion and exclusion criteria. The inclusion criteria were as follows: students with normal visual and hearing acuity and cognitive performance; with typical motor development; who had never been submitted to speech-language-hearing and psychopedagogical intervention; and whose school achievement presented a minimum average of 6.0 in Portuguese in two consecutive bimesters.

The exclusion criteria were illiterate students or those with underdeveloped reading; with an interdisciplinary diagnosis of specific learning disorder, attention-deficit/ hyperactivity disorder (ADHD), language development disorder (LDD), phonological disorder, and other genetic or neurological syndromes. This information was obtained from their school records.

The classes were selected for assessment based on the principal's indication. The application was scheduled with the teachers and education coordinator to avoid interfering with the classroom teaching routine. The students were invited to participate in the research and asked to keep their responses confidential.

All the study participants were submitted to the Assessment of Reading Fluency Performance (ADFLU, in Portuguese $)^{21}$. The instrument has a collection of narrative and expository texts, classified by the degree of difficulty, with easy and very easy texts, produced with high-frequency words whose syllables have low-complexity, simple structures.

The material was developed to be applied to firstto fourth-grade students. However, given the scarcity of reading fluency assessment instruments for fifth grade, this one was chosen, and the texts in it that required the highest level of fluency were applied. The texts used to analyze their reading were "Celebrating victory", "An adventure toward the Pacific", and "Letter from a friend", which belonged to level 3 , a category considered easy, whose narrative structure had at least 127 and at the most 194 words. The three texts were selected because of their similar textual complexity, to compare their reading fluency performance in three sequential readings.

The data analysis addressed the following reading fluency variables: CWPM, IWPM, TRT, and RS. The CWPM and IWPM were analyzed based on the reading made in 1 minute (60 seconds) of each text. The time was taken in seconds, counted from the first paragraph read in each text, and the minutes were converted into seconds for the TRT. The RS was calculated following what has been proposed by researchers ${ }^{22,23}$, in that the 
number of words in the text is multiplied by 60 seconds and divided by the TRT.

The texts were read individually, in a single session, in a separate room provided by the school, during school hours, each application lasting 10 to 20 minutes on average. The results of the three readings were recorded by the researchers. All readings were recorded as an auxiliary instrument to analyze the results, the productions/decoding, and the reading time. Hence, the readings were recorded only to check the word decoding mistakes, not requiring a full transcript. The data collection followed the same process and structure in both the public and private schools. The texts of the assessment instrument were presented to the students in print, with upper- and lowercase letters, without any change in their structure.

The students were instructed to read the full texts aloud, as they normally do it. At the end of each reading, they were asked what they had understood from the story, in the form of a conversation about the reading. Although it is not the objective of this study to research comprehension by having the story retold, this question was made to stimulate the interaction between the researcher and the student, which furnished complementary qualitative data to discuss the work.

The quantitative analysis data were computed in an Excel spreadsheet and later analyzed with statistical treatment. The variables were presented in mean, standard deviation (SD), minimum, and maximum values, and in the quartile distribution, represented by quartile $1\left(Q_{1}\right)$, quartile $3\left(Q_{3}\right)$, and median. The normality distribution was verified with the KolmogorovSmirnov test. For the intragroup comparison, all variables were compared between the three readings with the Kruskal-Wallis and ANOVA tests. For the intergroup comparison, the t-test and Mann-Whitney test were used. The significance level was set at $5 \%$ $(\leq 0.05)$, with analysis obtained in the Minitab software (version 17.1).

\section{RESULTS}

The results of the analysis of the reading fluency variables were presented in tables - the intragroup data in Table 1 and the intergroup data in Table 2 - to compare the performance of Gl and Gll. Thus, Table 1 shows the comparison of CWPM, IWPM, TRT, and RS of the first, second, and third readings. The analysis results indicated a statistically relevant difference in TRT in Gl and RS in Gll.

Table 2 shows the comparison between GI and GII in each variable studied, revealing a statistically significant difference in all analyses, for the three texts. 
Table 1. Distribution of the mean, standard deviation, maximum, and minimum values, with the variations of quartiles 1 and 3 and the median, in the intragroup comparison of the variables analyzed, regarding reading fluency performance in each group

\begin{tabular}{|c|c|c|c|c|c|c|c|c|c|c|}
\hline Variables & Groups & $\mathbf{N}$ & Mean & SD & Minimum & Q1 & Median & Q3 & Maximum & p-value \\
\hline CWPM-T1 & $\mathrm{Gl}$ & 25 & 86.9 & 31.9 & 14 & 66.5 & 94 & 107.5 & 144 & \\
\hline CWPM-T2 & $\mathrm{Gl}$ & 25 & 89.6 & 31.6 & 17 & 71.5 & 88 & 113 & 147 & $0.185^{\mathrm{a}}$ \\
\hline CWPM-T3 & $\mathrm{Gl}$ & 25 & 96.2 & 31.3 & 21 & 85 & 92 & 120 & 153 & \\
\hline IWPM-T1 & $\mathrm{Gl}$ & 25 & 3.8 & 2.4 & 0 & 2.5 & 4 & 6 & 8 & \\
\hline IWPM-T2 & $\mathrm{Gl}$ & 25 & 2.5 & 2.0 & 0 & 1 & 3 & 4 & 7 & $0.143^{b}$ \\
\hline IWPM-T3 & $\mathrm{Gl}$ & 25 & 3.2 & 3.0 & 0 & 1 & 3 & 5 & 10 & \\
\hline TRT-T1 & $\mathrm{Gl}$ & 25 & 122.2 & 67.9 & 73 & 89 & 107 & 125.5 & 359 & \\
\hline TRT-T2 & $\mathrm{Gl}$ & 25 & 150.3 & 89.8 & 82 & 101.5 & 129 & 156.5 & 439 & $0.002^{* b}$ \\
\hline TRT-T3 & $\mathrm{Gl}$ & 25 & 110.8 & 70.2 & 59 & 71.5 & 97 & 108.5 & 337 & \\
\hline RS-T1 & $\mathrm{Gl}$ & 25 & 90.6 & 26.3 & 26.5 & 75.8 & 90.8 & 109.1 & 130.6 & \\
\hline RS-T2 & $\mathrm{Gl}$ & 25 & 92.1 & 29.8 & 26.5 & 74.3 & 90.2 & 114.7 & 141.9 & $0.513^{\mathrm{a}}$ \\
\hline RS-T3 & $\mathrm{Gl}$ & 25 & 99.8 & 32.8 & 27.2 & 84.6 & 94.6 & 128.5 & 155.5 & \\
\hline CWPM-T1 & GII & 19 & 130.2 & 16.1 & 87 & 122 & 130 & 143 & 159 & \\
\hline CWPM-T2 & GII & 19 & 134.2 & 21.1 & 88 & 122 & 134 & 144 & 193 & $0.661^{\mathrm{a}}$ \\
\hline CWPM-T3 & GII & 19 & 135.9 & 21.4 & 87 & 122 & 134 & 147 & 153 & \\
\hline IWPM-T1 & GII & 19 & 1.1 & 1.3 & 0 & 0 & 1 & 2 & 4 & \\
\hline IWPM-T2 & GII & 19 & 1.2 & 1.1 & 0 & 0 & 1 & 2 & 4 & $0.844^{\mathrm{b}}$ \\
\hline IWPM-T3 & GII & 19 & 1.3 & 1.6 & 0 & 0 & 1 & 2 & 5 & \\
\hline TRT-T1 & GII & 19 & 75.1 & 11.4 & 58 & 66 & 75 & 83 & 108 & \\
\hline TRT-T2 & GII & 19 & 85.0 & 18.8 & 59 & 71 & 83 & 101 & 138 & $0.199^{\mathrm{b}}$ \\
\hline TRT-T3 & Gll & 19 & 79.7 & 18.2 & 61 & 69 & 76 & 85 & 141 & \\
\hline RS-T1 & GII & 19 & 129.5 & 18.2 & 88.3 & 114.9 & 127.2 & 144.5 & 164.4 & \\
\hline RS-T2 & GII & 19 & 142.8 & 29.4 & 84.3 & 115.2 & 140.2 & 163.9 & 197.2 & $0.012^{\star a}$ \\
\hline RS-T3 & Gll & 19 & 119.3 & 20.6 & 65.1 & 108 & 120.7 & 133.0 & 150.4 & \\
\hline
\end{tabular}

*ANOVA (a) and Kruskal-Wallis test (b) with significance set at p-value $\leq 0.05$

Units of measurement of the variables: CWPM and IWPM: words; TRT and RS: seconds

Captions: CWPM: correct words per minute, IWPM: incorrect words per minute, TRT: total reading time, RS: reading speed, T1: first reading, T2: second reading, T3: third reading, N: number of participants, SD: standard deviation, Q1: quartile 1, Q3: quartile 3

Table 2. Distribution of the mean, standard deviation, maximum, and minimum values, with the variations of quartiles 1 and 3 and the median, in the intergroup comparison of the variables analyzed, regarding reading fluency performance between Group I and Group II

\begin{tabular}{|c|c|c|c|c|c|c|c|c|c|c|}
\hline Variables & Groups & $\mathrm{N}$ & Mean & SD & Minimum & Q1 & Median & Q3 & Maximum & $\mathrm{p}$-value \\
\hline \multirow{2}{*}{ CWPM-T1 } & $\mathrm{Gl}$ & 25 & 86.9 & 31.9 & 14 & 66.5 & 94 & 107.5 & 144 & \multirow{2}{*}{0.000 *a } \\
\hline & GII & 19 & 130.2 & 16.1 & 87 & 122 & 130 & 143 & 159 & \\
\hline \multirow{2}{*}{ IWPM-T1 } & $\mathrm{Gl}$ & 25 & 3.8 & 2.4 & 0 & 2.5 & 4 & 6 & 8 & \multirow{2}{*}{$0.003^{\star b}$} \\
\hline & GII & 19 & 1.1 & 1.3 & 0 & 0 & 1 & 2 & 4 & \\
\hline \multirow{2}{*}{ TRT-T1 } & $\mathrm{Gl}$ & 25 & 122.2 & 67.9 & 73 & 89 & 107 & 125.5 & 359 & \multirow{2}{*}{$0.000^{* b}$} \\
\hline & GII & 19 & 75.1 & 11.4 & 58 & 66 & 75 & 83 & 108 & \\
\hline \multirow[b]{2}{*}{ RS-T1 } & $\mathrm{Gl}$ & 25 & 90.6 & 26.3 & 26.5 & 75.8 & 90.8 & 109.1 & 130.6 & \multirow{2}{*}{0.000 *a } \\
\hline & GII & 19 & 129.5 & 18.2 & 88.3 & 114.9 & 127.2 & 144.5 & 164.4 & \\
\hline \multirow{2}{*}{ CWPM-T2 } & $\mathrm{Gl}$ & 25 & 89.6 & 31.6 & 17 & 71.5 & 88 & 113 & 147 & \multirow{2}{*}{$0.000^{* a}$} \\
\hline & GII & 19 & 134.2 & 21.1 & 88 & 122 & 134 & 144 & 193 & \\
\hline \multirow{2}{*}{ IWPM-T2 } & $\mathrm{Gl}$ & 25 & 2.5 & 2.0 & 0 & 1 & 3 & 4 & 7 & \multirow{2}{*}{$0.027^{\star b}$} \\
\hline & GII & 19 & 1.2 & 1.1 & 0 & 0 & 1 & 2 & 4 & \\
\hline \multirow{2}{*}{ TRT-T2 } & $\mathrm{Gl}$ & 25 & 150.3 & 89.8 & 82 & 101.5 & 129 & 156.5 & 439 & \multirow{2}{*}{$0.000^{\star b}$} \\
\hline & Gll & 19 & 85.0 & 18.8 & 59 & 71 & 83 & 101 & 138 & \\
\hline \multirow{2}{*}{ RS-T2 } & $\mathrm{Gl}$ & 25 & 92.1 & 29.8 & 26.5 & 74.3 & 90.2 & 114.7 & 141.9 & \multirow{2}{*}{0.000 *a } \\
\hline & Gll & 19 & 142.8 & 29.4 & 84.3 & 115.2 & 140.2 & 163.9 & 197.2 & \\
\hline \multirow{2}{*}{ CWPM-T3 } & $\mathrm{Gl}$ & 25 & 96.2 & 31.3 & 21 & 85 & 92 & 120 & 153 & \multirow{2}{*}{$0.000^{* a}$} \\
\hline & GII & 19 & 135.9 & 21.4 & 87 & 122 & 134 & 147 & 153 & \\
\hline \multirow{2}{*}{ IWPM-T3 } & $\mathrm{Gl}$ & 25 & 3.2 & 3.0 & 0 & 1 & 3 & 5 & 10 & \multirow{2}{*}{$0.025^{\star b}$} \\
\hline & Gll & 19 & 1.3 & 1.6 & 0 & 0 & 1 & 2 & 5 & \\
\hline \multirow{2}{*}{ TRT-T3 } & $\mathrm{Gl}$ & 25 & 110.8 & 70.2 & 59 & 71.5 & 97 & 108.5 & 337 & \multirow{2}{*}{$0.041^{* b}$} \\
\hline & GII & 19 & 79.7 & 18.2 & 61 & 69 & 76 & 85 & 141 & \\
\hline \multirow{2}{*}{ RS-T3 } & $\mathrm{Gl}$ & 25 & 99.8 & 32.8 & 27.2 & 84.6 & 94.6 & 128.5 & 155.5 & \multirow{2}{*}{$0.021^{* a}$} \\
\hline & GII & 19 & 119.3 & 20.6 & 65.1 & 108 & 120.7 & 133.0 & 150.4 & \\
\hline
\end{tabular}

*T-test (a) and Mann-Whitney test (b) with significance set at p-value $\leq 0.05$

Units of measurement of the variables: CWPM and IWPM: words; TRT and RS: seconds

Captions: CWPM: correct words per minute, IWPM: incorrect words per minute, TRT: total reading time, RS: reading speed, T1: first reading, T2: second reading, T3:

third reading, N: number of participants, SD: standard deviation, Q1: quartile 1, Q3: quartile 3 


\section{DISCUSSION}

A significant difference was found in the intragroup comparison regarding TRT in Gl when the three texts were compared. The highest mean was obtained in the reading of $\mathrm{T} 2$, which was the longest of the three. The analysis of the texts revealed that $\mathrm{T} 3$ was the shortest text, with 153 words, whereas the longest one was T2, with 194 words; T1 had 159 words.

It also revealed that the mean TRT of Gll students behaved likewise, regarding the T2 performance analysis, though with no statistically significant difference. Nonetheless, the TRT values obtained by GIl were not significantly different between the three texts. The data suggest that the discrimination and access to information while decoding T2 influenced the TRT, especially among the private-school students.

The students' performance was close to the median TRT with a balanced distribution between $Q_{1}$ and $Q_{3}$ in the text reading. However, the performance of some students was below the expected in comparison with their group in T1 and T2, with a greater concentration in $\mathrm{Q}_{3}$ for T3 among the public-school students. The distribution among private-school students was balanced between $Q_{1}$ and $Q_{3}$ for the three texts, although one student had a performance above the median in T3, reading it in a shorter time. This performance can be explained by the complexity of the words in each text and the frequency of access to them, keeping the fluent readers' high decoding level while making this process more difficult for students with an inferior performance in this skill 16,24 .

Even though T2 is the longest text, it has a higher percentage of simple words, with monosyllable and disyllable structures. $\mathrm{T} 1$ is similar in terms of word structure and frequency, though with fewer words than T2. As for T3, the number of words is similar to that of $\mathrm{T} 1$, though with more complex word structures than T1 and T2.

Based on this analysis, it can be stated that there is a lexical balance in the chosen texts because, even if there was a difference in the number or structure of words, none of the three texts had both characteristics. It is also important to remember that the three texts used in the assessment belong to the same degree of difficulty, according to what is proposed in the instrument. Another point to consider is that the mean values of both public- and private-school students behaved likewise - despite the different values, which can be explained by the influence of predictive decoding factors, such as vocabulary, access to phonological and lexical routes, phonological processing, and even fluency and accuracy ${ }^{9,25,26}$.

According to the analysis of the texts and the possible relationships with the results identified in the students' readings, the overall comprehension of $\mathrm{T} 1$ proved to be better than that of the other two (T2 and T3), as the students managed to retell it in more detail. Nevertheless, the analysis or recording of the retold story was not analyzed in this study, remaining only as an observation made by the researchers.

In the same perspective, it was also identified that some students had greater difficulty with longer, more complex, or low-frequency words, in the three texts. This characteristic was present in both groups, though more evident in the public-school students. Longer and more complex (tri- and polysyllable) words occurred only once in the texts (e.g., T1: temporada [season], comemoração [celebration], and corrêssemos [if we ran]; T2: empoeiradas [dusty] and planícies [plains]; T3: caminhada [stroll], acampamento [camp], and prestativos [helpful]), whereas shorter (disyllable) words occurred more often in the texts (e.g., T1: pizza, troféus [trophies]; T2: vagão [train wagon], noite [night]; T3: melhor [better], treino [training]). Words that are not as frequent and whose syllable structures are more complex make decoding more difficult - even when they are shorter or occur less often in the text ${ }^{16}$. The access to a word and its recognition are related not only to decoding; they also depend directly on factors such as vocabulary, as the index of words present in a child's lexicon is an access-facilitating factor, depending on their previous contact with the word and the consolidation of its significance and meaning ${ }^{13,27}$.

There was a significant difference in GII in the comparison of the RS between the three texts. The highest mean was that of T2 - which had more words and a greater percentage of simple words. The RS seemingly did not interfere negatively with the CWPM, as the performance means in this group grew from one text to the next. The data suggest that the increase in text complexity and length did not interfere directly with the number of CWPM ${ }^{8}$.

The performance distribution in relation to the RS median and quartiles in the two groups indicates a greater distribution in $\mathrm{Q}_{3}$ for $\mathrm{Gl}$ in $\mathrm{T} 2$ and T3. This suggests a balanced performance in the lexicon access speed to decode T2 and T3 among the Gl students. As for GIl, this distribution into quartiles is balanced for the three texts. Even if there is a difference in scores in the median and quartiles in the comparison between the 
groups, the intergroup analysis revealed similar performances in the access to lexical information, which reflected on reading fluency.

An increase in CWPM from one text to the other was identified in $\mathrm{Gl}$ - i.e., the means increased from T1 toT2, and from this one to T3. Even though the means were lower in Gl than in Gll, both groups had the same improvement behavior as they read. Nonetheless, the number of IWPM in GI in T1, T2, and T3 was higher than in Gll. The increase in the CWPM rate suggests that exposure to reading potentializes the reading performance, decreasing the number of IWPM, regardless of text complexity and length ${ }^{4}$. It can also be inferred that the groups are improving their reading fluency, which demonstrates a positive point regarding the two schools. However, measures should be implemented in the regular program of public schools to potentialize their students' performance ${ }^{28,29}$.

The analysis of IWPM performance according to the distribution per median and quartiles indicate a greater balance in the distribution and dispersion within the groups. Despite the trend toward a performance concentration in $Q_{1}$ for Gll, both had greater homogeneity among students. On the other hand, when the distribution is directed to the CWPM rate, there is a greater performance variability in $\mathrm{Gl}$, as well as dispersion of students.

The fifth-grade academic content exposes the students to word frequency and regularity rates according to the approach and teaching material used in each educational setting. Even though the Ministry of Health has established the essential content to be covered in each grade, regardless of the source of the school's financing, variations are often identified?. In this perspective, the public-school students had greater difficulty correctly decoding words from the texts used in this study than those from private schools. This indicates an inferior reading fluency performance, as the accurate decoding, analyzed in terms of correct words, is concentrated in $\mathrm{Q}_{1}{ }^{17}$.

The comparison between $\mathrm{Gl}$ and Gll revealed a significant difference in all the variables analyzed. These data demonstrate the existing difference between the public- and private-school reading profiles when their performance is compared. The cognitive demands required from private-school students are greater than those from public schools. This fact suggests a reflection of the greater reading potential of privateschool children. The exposure to school reading tasks enables their students to develop this skill, leading to a reading practice with less cognitive demand to perform their tasks. Moreover, they consolidate the lexical memory and broaden their access possibilities ${ }^{24}$.

The better performance of the private school in all the variables can be explained by its educational approach from kindergarten. The teaching methodology of the private institution where the research was conducted teaches to read and write based on phonological awareness. This may have helped develop a more favorable fluency, as these children were specifically stimulated to learn reading from early childhood, which was possibly a facilitating factor for these students?

Another point for reflection in the data is the access to reading the children of different socioeconomic levels have since early childhood - i.e., the number of books to which these students have access throughout life. Studies indicate that the greater the contact with books and the earlier the children's access to them, the better their reflection on language performance and, consequently, on reading ${ }^{30}$. Thus, this information suggests that the socioeconomic and cultural level can outline the reading profile, as families with a lower socioeconomic level usually have fewer books and therefore have less access to this encouraging stimulus for children in social vulnerability ${ }^{31}$.

Another information to consider refers to the TRT, which was significantly lower in private-school students, and the RS, which was at the same time significantly lower in public-school students. These time and speed variables interfere directly with the melodic variation in reading, which increases progressively as the students progress to the subsequent grades in school, with higher results precisely in the fifth grade ${ }^{32}$.

The analysis of the median $\left(50^{\text {th }}\right.$ percentile) as a cutoff score reference for the performance in CWPM, IWPM, TRT, and RS in the two compared groups reveals a difference between the three readings, enabling the identification of the performance distribution per school group. Hence, the median provides a measure of the overall performance of the class, indicating the students who have difficulties in specific skills, as they are classified in the $25^{\text {th }}$ percentile ${ }^{19}$.

The mean values make clear the higher performance of the private-school students, whereas they also identify the gradual progress of the public-school students in the skills analyzed. On the other hand, these students' gradual progress may be related to the characteristics of these texts and not necessarily to their immediate reading evolution. Educational adjustments 
and health and education prevention and promotion measures, associated with reading monitoring practices, are believed to be able to enhance these students' performance and maximize their learning and training possibilities ${ }^{20}$.

Lastly, other aspects must be broadened in future research, such as the investigation between reading fluency and comprehension, as the performance in the variables studied tends to interfere not only with fluency but also comprehension ${ }^{10}$. Furthermore, the investigation on reading fluency should continue, approaching not only fifth-grade classes, with larger samples than the limited one of this study, but also the other grades in elementary and middle school. Another limitation in this study was the small number of participants and their selection method. The collection should be enlarged, encompassing more public and private schools. The considerations obtained in this study apply only to the cases researched and cannot be generalized.

\section{CONCLUSION}

This research characterized the reading fluency performance of fifth-grade students of two elementary schools with different sources of financing (public and private), considering the CWPM, IWPM, TRT, and RS. The analysis per group revealed a significant difference in the TRT between the texts in the group of publicschool students, and in RS between the texts in the group of private-school students. The comparison between the public- and private-school classes showed that the private-school students had a higher performance than those from the public school, highlighting the need for stimulation and intervention measures in this population.

\section{REFERENCES}

1. Rasinski TV. Readers who struggle: why many struggles and a modest proposal for improving their reading. Read Teach. 2017;70(5):519-24.

2. Santos AAA, Ferraz AS, Rueda FJM. Relações entre a compreensão de leitura e as habilidades metalinguísticas. Psicol Esc Educ. 2018;22(2):301-9.

3. Gombert JE. Metalinguistic development. Chicago: University of Chicago Press, 1992.

4. Seabra AG, Dias NM, Montiel JM. Estudo fatorial dos componentes da leitura: velocidade, compreensão e reconhecimento de palavras. Psicol. USF. 2012;17(2):273-83.

5. Aldhanhani ZR, Abu-Ayyash EAS. Theories and research on oral reading fluency: what is needed? Theory Pract Lang Stud. 2020;10(4):379-88.

6. Tighe LE, Schatschneider C. A quantile regression approach to understanding the relations among morphological awareness, vocabulary, and reading comprehension in adult basic education students. $J$ Learn Disabil. 2016;49(4):424-36.

7. Silva C, Rodriguez LM. Reading performance markers of students from public and private elementary school. Braz $\mathrm{J}$ Dev. 2021;7(2):17299-314.

8. Yilmaz M, Kadan Ö. An action research aiming to reveal the effects of paired reading on eliminating reading difficulties. Bartin University J Facul Educ. 2019;8(1):231-44.

9. Coltheart M, Rastle K, Perry C, Ziegler J. DRC: a dual route cascaded model of visual word recognition and reading aloud. Psychol Rev. 2001;108(1):204-56.

10. Cunha VLO, Martins MA, Capellini SA. Relação entre fluência e compreensão leitora em escolares com dificuldades de aprendizagem. Psic: Teor. Pesq. 2017;33(e33314):1-8.

11. Martins MA, Capellini SA. Relation between oral reading fluency and reading comprehension. CoDAS. 2019;31(1):1-8.

12. Carretti B, Motta E, Re AM. Oral and written expression in children with reading comprehension difficulties. J Learn Disabil. 2016;49(1):65-76.

13. Barbosa ALA, Soares HB, Azoni CAS. Development of a vocabulary-screening tool for children 3 to 7-years of age. Audiol. Commun. Res. 2019;24:e2131.

14. Cunha VLO, Capellini SA. Characterization of reading comprehension performance of students from 3rd to 5th grades of elementary school. Rev. CEFAC. 2016;18(4):941-51.

15. Martins MA, Capellini SA. Fluência e compreensão da leitura em escolares do 3 ㅇ ao 5 음 ano do ensino fundamental. Estud. psicol. 2014;31 (4):499-506.

16. Lee J, Yoon SY. The effects of repeated reading on reading fluency for students with reading disabilities: a meta-analysis. J Learn Disabil. 2017;50(2):213-24.

17. Stevens EA, Walker MA, Vaughn S. The effects of reading fluency interventions on the reading fluency and reading comprehension performance 
of elementary students with learning disabilities: a synthesis of the research from 2001 to 2014. J Learn Disabil. 2017;50(5):576-90.

18. OECD: Organização para Cooperação e Desenvolvimento Econômico. PISA 2018: Insights and Interpretations. [homepage on the internet] 2019. [accessed $2020 \mathrm{dec}$ 15]. Available at: <https://www.oecd.org/pisa/PISA\%202018\%20 Insights $\% 20$ and $\% 20$ Interpretations $\% 20$ FINAL\%20PDF.pdf>.

19. Oakhill JV, Cain K. The precursors of reading ability in young readers: evidence from a four-year longitudinal study. Sci Stud Read. 2012;16(2):91-121.

20. Zuanetti PA, Novaes CBN, Fukuda MTH. Intervention based on shared story reading: effect on low and high challenge reading and writing tasks. CoDAS. 2021;33(3):e20200129.

21. Martins MA, Capellini SA. Avaliação do desempenho em fluência de leitura (ADFLU). Ribeirão Preto: Book Toy, 2018.

22. Condemarin $M$, Blomquist $M$. Dislexia: manual de leitura corretiva. Porto Alegre: Editora Artes Médicas, 1989.

23. Ramos CS. Avaliação de leitura em escolares com indicação de dificuldade de leitura e escrita [thesis]. São Paulo (SP): Universidade Federal de São Paulo; 2005.

24. Souza CA, Escarce AG, Lemos SMA. Reading competence of words and pseudo words, school performance and listening skills in primary schools. Audiol. Commun. Res. 2019;24:e2018.

25. Alves LM, Souza HTV, Souza VO, Lodi BF, Ferreira MCM, Siqueira CM et al. Phonological processing in individuals with attention deficit hyperactivity disorder. Rev. CEFAC. 2014;16(3):874-82.

26. Barbosa VM, Silva C. Correlation between receptive vocabulary skill, syntactic awareness, and word writing. Rev. CEFAC. 2020;22(3):e2420.

27. Colombo RC, Cárnio MS. Reading comprehension and receptive vocabulary in Elementary School students with typical development. CoDAS. 2018;30(4):e201700145.

28. Santos VAP. Teacher mediator of reading: the importance and necessity of teacher training for the teaching of reading. Braz J Dev. 2021;7(1):7279-91.

29. Monteiro SM, Soares M. Processos cognitivos na leitura inicial: relação entre estratégias de reconhecimento de palavras e alfabetização. Educação e Pesquisa. 2014;40(2):449-66.
30. Mendes ECCS, Brunoni D. Competência em leitura: interface entre contextos psicossocial, familiar e escolar. São Paulo (SP): Editora Mackenzie; 2015.

31. Durkin K, Conti-Ramsden G. Young people with specific language impairment: A review of social and emotional functioning in adolescence. Child Lang Teach Ther. 2010;26(2):105-21.

32. Celeste LC, Pereira ES, Pereira NRRP, Alves LM. Prosodic parameters of reading in 2 nd to 5 th grade students. CoDAS. 2018;30(1):e20170034. 